\title{
Mimesofobia y retóricas del contagio: el miedo al poema como instrumento político en la República de Platón \\ Mimesophobia and rhetorics of the contagion: fear of the poem as a political instrument in Plato's Republic
}

\author{
IVÁN DE LOS RÍOS GUTIÉRREZ \\ Universidad Autónoma de Madrid \\ ivan.delosrios@uam.es
}

Recibido: 31/07/2019 - Aceptado: 31/01/2020

DOI https://doi.org/10.20318/fons.2019.4908

\begin{abstract}
Resumen
El presente trabajo analiza el modo en que el miedo al contagio del arte y su dimensión política se convierten, en la República de Platón, en un instrumento retórico y pedagógico al servicio de una nueva configuración racional del individuo y de la comunidad. Un instrumento que se alimenta de la pasión política por excelencia: el miedo, y en concreto, el miedo a la contaminación, a la enfermedad y a la pérdida de control sobre uno mismo.
\end{abstract}

Palabras clave: mímesis, Platón, contagio del arte, pasiones políticas

\section{Abstract}

This paper focuses on fear of artistic contagion and its political dimension in Plato's Republic. For Plato fear is a rhetorical and pedagogical device for a new rational configuration of individuals and community. An instrument that feeds on the political passion par excellence: fear, and, more precisely, fear of contagion, fear of disease and loss of self-control.

Keywords: mimesis, Plato, artistic contagion, political passions

En su ensayo Inmunidad, Eula Biss afirma que el miedo al contagio se basa en la idea «de que algo puede transmitirnos su esencia por mero contacto. Nos parece que el contacto con una sustancia contaminante puede dejarnos contaminados para siempre, y los contaminantes que más tememos son fruto de nuestras propias manos» (BISS 2015, 52-53, cursivas nuestras). Pocas cosas tan próximas, tan contagiosas y tan fruto de nuestras manos como aquellas obras de arte que, al decir de Platón, estragan la mente y arruinan el espíritu de cualquier auditorio desprovisto de un antídoto capaz de desvelar su auténtica naturaleza ${ }^{1}$ ¿ ¿Cuál es la auténtica naturaleza del arte y por qué es necesario un correctivo contra su influjo? Desde la Antigua Grecia, y de un modo tan bello como inquietante, la poesía mimética arrebata, hechiza y subyuga al

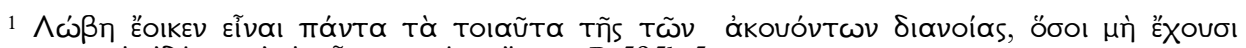

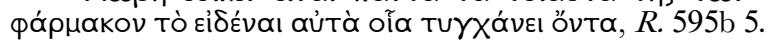

ПНГН/FONS 4 (2019), 107-122

ISSN 2445-2297 www.uc3m.es/pege

I. DE los Ríos GuTiÉRrez, Mimesofobia DOI https://doi.org/10.20318/fons.2019.4908 
espectador mediante un contacto audiovisual susceptible de ser descrito mediante la retórica bélico-inmunitaria de la invasión y el contagio: la mímesis penetra nuestros poros, invade nuestros cuerpos, excita nuestras pasiones y amenaza con destruir el orden siempre frágil de la unidad psíquica. El presente trabajo analiza el modo en que el miedo al contagio del arte y su dimensión política se convierten, en la República de Platón, en un instrumento retórico y pedagógico al servicio de una nueva configuración del individuo y de la comunidad. Un instrumento que se alimenta de la pasión política por excelencia: el miedo, y en concreto, el miedo a la contaminación, a la enfermedad y a la pérdida de control sobre uno mismo.

Desde este marco de intereses, intentaremos responder a tres preguntas: i) ¿Cuál es el contexto de aparición de la mímesis como problema filosófico y político en la República de Platón?; ii) ¿En qué consisten los poderes supuestamente devastadores de la mímesis?; iii) ¿En qué sentido el miedo a la mímesis o mimesofobia puede ser concebido y empleado como instrumento de manipulación política? En otras palabras: ¿en qué medida el pathos de la mímesis, además de un pathos psicológico, es una pasión política?

\section{Pesimismo antropológico y optimismo pedagógico: la concepción nosológica del Estado en la República de Platón}

En sus Quince lecciones sobre Platón, Mario Vegetti (2012, 101-121) sugiere que una de las diferencias más sutiles e interesantes entre Tucídides y el fundador de la Academia es el optimismo pedagógico del filósofo frente al pesimismo antropológico del historiador. Una disonancia, sin duda, digna de atención, porque destaca sobre un diagnóstico común frente a la realidad política de la que ambos son herederos. La mirada atenta del historiador y la insoportable agudeza del filósofo arrojan una misma luz sobre la experiencia del fracaso ateniense. Y ese fracaso viene vehiculado por una de las metáforas más fértiles en la historia del pensamiento occidental: «la verdadera ciudad es la que acabamos de describir: es una ciudad sana, por decirlo así»

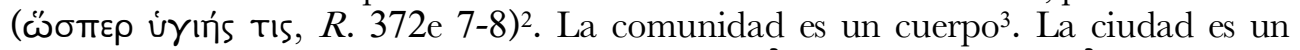
cuerpo y dicho cuerpo está afiebrado e infecto ( $\phi \lambda \varepsilon \gamma \mu \alpha i ́ v o v \sigma \alpha v$ mó $\lambda ı v)$. La polis ha caído enferma y, en su enfermedad, sucumbe como proyecto de configuración de una comunidad homogénea, armónica y compacta que garantice el orden y la justicia entre sus miembros. Ahora bien, ¿por qué fracasa la comunidad? ¿Por qué enferma la polis una y otra vez, arrastrada por la fiebre, el vértigo y la infección, como un alma excesivamente asociada al orden de lo sensible ${ }^{4}$ ¿Cuáles son las causas que corrom-

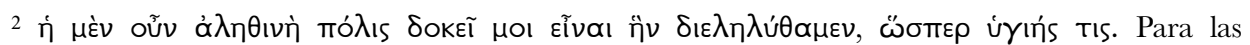
traducciones de Platón, emplearemos las versiones de Gredos en todos los casos, exceptuando el diálogo República, para el que emplearemos la versión de Pabon-Galiano en Alianza.

${ }^{3}$ Sobre el papel de las metáforas en el lenguaje filosófico, ver BLUMENBERG 2018. Sobre la conexión entre enfermedad y metáfora, ver LAín ENTRALGO 1961 y SONNTAG 2012.

${ }^{4}$ «¿No es esto lo que decíamos hace un rato, que el alma cuando utiliza el cuerpo para observar algo, sea por medio de la vista o por medio del oído, o por medio de algún otro sentido, pues en eso consiste lo

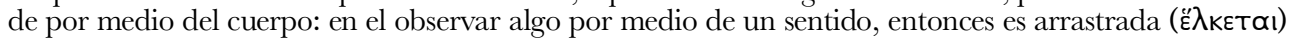


pen la salud del cuerpo social y cuáles sus remedios? Frente esta pregunta, Platón y Tucídides parecen compartir no sólo una concepción nosológica del Estado, sino también una antropología de corte pesimista. Un pesimismo antropológico que destila

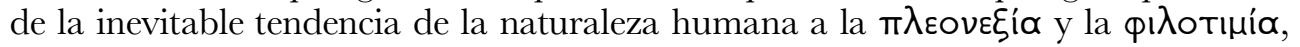
i.e., al exceso ilimitado en la voluntad de poder y de gloria, en la ambición y en la codicia:

A juicio de Platón, la ciudad estaba enferma. La propia empresa de la civilización griega por entero, culminada en la experiencia ateniense, de construir una experiencia política, la polis, homogénea en su seno, carente de conflictos, capaz de representar el espacio primordial de identificación y de reconocimiento del individuo ante sí mismo como ciudadano, al margen de las diversas pertenencias de clase y de clan familiar, una empresa tal parecía abocada al fracaso (VEGETTI 2012, 101).

El primer paso en el diagnóstico de la enfermedad lo había dado Tucídides al denunciar que la política imperialista de Atenas convierte a la polis en una "ciudad tirana” (Th. II 62, 3; VEGETTI 2012, 102). Ante los ojos de Platón, jóvenes y aún perplejos, el imperialismo ateniense condujo a la terrible Guerra del Peloponeso y al conflicto civil, que se propagó por toda Grecia como un cáncer huracanado. Por eso, afirma Tucídides, la guerra ya no puede ser vista entre los hombres más que como un

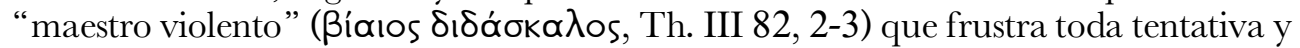
toda esperanza de consecución de una ciudad armónica, cohesionada y articulada en torno a la virtud política. En esta desesperanza reside, precisamente, el pesimismo de ambos autores. Tucídides entiende que los conflictos bélicos evidencian sin remedio la naturaleza oculta del más terrible y maravilloso ${ }^{5}$ de cuantos animales caminan sobre la faz de la tierra, y así lo expresa por boca del embajador ateniense en su célebre diálogo con los Melios: «Pensamos, en efecto, como mera opinión en lo tocante al mundo de los dioses y con certeza en el de los hombres, que siempre se tiene el mando, por una imperiosa ley de la naturaleza, cuando se es más fuerte» ${ }^{6}(\mathrm{~V} 105,2)$. Esa imperiosa ley de la naturaleza que, al decir de los atenienses, afecta a dioses y a hombres, no es otra que la ley del más fuerte, el célebre teorema del poder que empleará Trasímaco en la República y que Tucídides detallará con precisión al describir las consecuencias morales de la guerra civil:

Muchas calamidades se abatieron sobre las ciudades con motivo de las luchas civiles, calamidades que ocurren y que siempre ocurrirán mientras la naturaleza humana sea

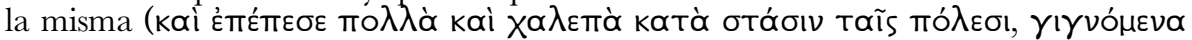

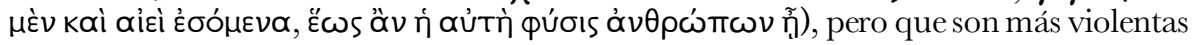

por el cuerpo hacia las cosas que nunca se presentan idénticas, y ella se extravía, se perturba como si

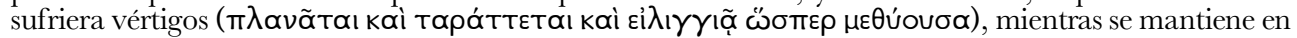
contacto con esas cosas?», Phd. 79c-d.

${ }^{5}$ El célebre adjetivo empleado por Sófocles en Ant. 332 para referirse al ser humano es atribuido por

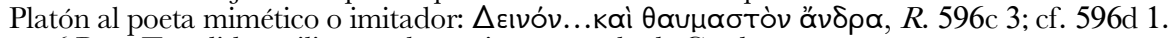

${ }^{6}$ Para Tucídides utilizamos la versión española de Gredos. 
o más benignas y diferentes en sus manifestaciones según las variaciones de las circunstancias que se presenten en cada caso (III 82, 2).

La causa de todos los males que trae el conflicto civil no es otra, entonces, que «el deseo de poder inspirado por la codicia y la ambición», un deseo imperante a través de los siglos que interesará a autores tan distantes (pero no tan distintos) como Calicles y Nietzsche ${ }^{7}$. La $\pi \lambda \varepsilon o v \varepsilon \xi i ́ \alpha$ es el motor que pone en movimiento la conducta humana $y$, en este sentido, el animal racional está ya siempre condenado a sucumbir cíclicamente al carácter devastador de sus viles pasiones en tiempos de guerra y conflicto, frustrando ab initio toda posibilidad de cohesión racional, psíquica y social. Platón sigue de cerca las enseñanzas del historiador ateniense ${ }^{8}$, pero no tarda en matizarlas con el fin de establecer una estrategia de compensación que supere los riesgos paralizantes que todo pesimismo antropológico supone para el progreso del género humano. El filósofo parece dispuesto a aceptar que la naturaleza humana tiende a la satisfacción de apetitos egoístas e irracionales como la codicia, la ambición o del deseo de poder, pero ello no le impide diseñar y conducir hasta sus máximas consecuencias un optimismo pedagógico de hondo calado en la historia del pensamiento Occidental:

Llegados a este punto, sin embargo, el pronóstico de Platón difería del de Tucídides. La naturaleza humana no es "necesaria", es decir, inmutable. El alma puede responder a un condicionamiento educativo capaz de modificar los equilibrios interiores, reforzando la racionalidad cooperativa en detrimento de las pulsiones competitivas y agonales... Tal vez también había sido esta la esperanza de Sócrates, solo que para Platón el círculo se recorría en sentido contrario. El fracaso socrático se debió a la ilusión de poder cambiar la ciudad actuando directamente sobre el alma de los individuos que la componían. Platón pensaba en cambio que el reacondicionamiento educativo de los individuos únicamente era posible de resultas de una empresa colectiva que la ciudad entera tenía que gestionar. No podía ser que el hombre justo tuviera que hacer justa a la ciudad; sólo una ciudad justa estaba en condiciones de hacer justos, es decir, racionales, a sus ciudadanos, pero existía el peligro de que ello derivase en un círculo vicioso [...]. La salida del círculo vicioso no podía entonces más que consistir en la cuestión del poder, la ciudad enferma requería médicos capaces de curarla (VEGETTI 2012, 103-104).

Enfermedad y educación. Estos dos conceptos fundamentales nos orientan ya hacia el núcleo temático de este trabajo: la concepción epidemiológica de la mímesis y el miedo a su contagio como instrumento de domesticación en la República de Platón. Enfermedad y "reacondicionamiento educativo": la enfermedad como metá-

${ }^{7}$ Sobre el teorema del poder y las relaciones entre Calicles y Nietzsche pueden consultarse LISI Bereterbide 2008, Carrasco 2011, Enguita 2017, Frías 2000 y el clásico trabajo de Menzel 1964. Agradezco al alumno del Máster en Democracia y Orden Mundial de la UAM (2019), Francisco Sánchez Andrada, la orientación bibliográfica y las claves teóricas que se desprenden de sus investigaciones sobre el recorrido histórico de la noción de $\pi \lambda \varepsilon \circ \boldsymbol{v}_{\varepsilon} \xi \mathfrak{i} \alpha$, desde Tucídides hasta la democracia liberal.

${ }^{8}$ Sobre las conexiones entre Tucídides y Platón, ver EIRE 1990. 
fora de la descomposición interna del organismo social y la educación como alternativa posible para la recuperación, el mantenimiento y el florecimiento de la salud. En otras palabras: la enfermedad entendida como desequilibrio entre los núcleos motivacionales que constituyen la unidad psíquica según la célebre psicología tripartita de Republica IV y X, y la educación como antídoto que elimina el imperio de lo irracional en el orden psíquico, favoreciendo la configuración de un alma justa, armónica y virtuosa. Un alma que, como sabemos, puede ser contemplada isomórficamente desde la perspectiva más amplia de la polis en su integridad 9 .

Si las consideraciones previas son acertadas, el problema de la mímesis se convierte en un asunto filosófico y político de primer orden. En efecto, si la decadencia humana no es necesaria ni inmutable, parece que incluso las tendencias más arraigadas de la mentalidad primitiva griega podrían ser el resultado de una historia lenta pero eficaz, de un adoctrinamiento sordo pero obstinado a través de los siglos, las prácticas y los cuerpos individuales sometidos al hechizo constante de los múltiples estímulos externos que ofrecen tanto el arte como la naturaleza. Sobre todo el arte: el arte de los poetas imitativos que han educado a Grecia durante siglos. Desde esta perspectiva, incluso las más espontáneas de nuestras pasiones (la ambición o el deseo de poder, por ejemplo, pero también la esperanza o el miedo) emergerían de una genealogía cuyo desentrañamiento ha de corresponder al fundador de ciudades. En manos de Platón, esa genealogía pasa por el desmantelamiento de la experiencia poética homérica en sentido amplio y, por ende, por una purga severa del concepto de mímesis, pues son los poetas, y en particular Homero ${ }^{10}$, los auténticos educadores de una Grecia que sucumbe cíclicamente a sus más terribles pasiones. Si el presente político tiene historia; si el alma humana tiende, pero no está fatalmente condenada al desastre por su inevitable propensión a la ambición y a la codicia de las que emerge todo fanatismo

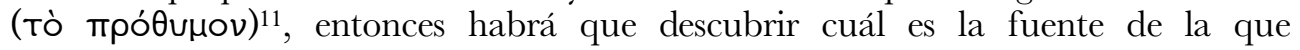
tradicionalmente se nutren las tendencias constitutivas de una comunidad que reiteradamente cede ante la enfermedad y el desastre. Tal vez entonces descubramos que, lejos de ser un modelo invariable y repetible en la multiplicidad de individuos del género humano, la identidad psico-política del Estado puede ser descrita como una entidad maleable de extraordinaria plasticidad que, en cuanto tal, es susceptible de ser moldeada mediante la educación en beneficio del imperio violento de las pasiones más bajas o, al revés, en la dirección del gobierno sereno de los más nobles apetitos. A juicio de Platón, por tanto, la enfermedad de la polis solo es curable siguiendo un método ordenado y preciso de distanciamiento teórico que combina la diagnosis médica, la pedagogía psico-política y la ingeniería social: i) detectar las causas de la enfermedad; ii) minimizar o neutralizar su presencia en los procesos de formación

${ }^{9}$ Sobre el isomorfismo de la República puede consultarse FerRARi 2003, VegETTI 1998, III y WiLLIAMS 2006, 141-153.

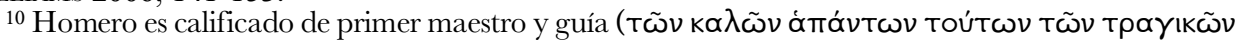

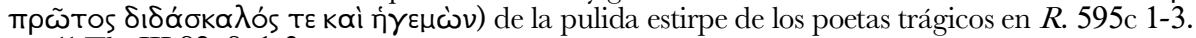

11 Th. III 82, 8, 1-3. 
emocional e intelectual de los ciudadanos; e iii) inocular en el alma humana una reforma educativa mediante el establecimiento de una nueva serie de principios, valores, normas y apetitos inerciales que, en lugar de fortalecer la competitividad, la codicia y la guerra, tiendan a promover la armonía, la virtud, la justicia y la camaradería. En otras palabras: el problema filosófico de Platón es, sin duda, un problema médico. Pero es un problema médico porque, ante todo, se trata de un problema pedagógico. ¿Cómo educar a las clases gobernantes de los filósofos que habrán de posibilitar y perpetuar la justicia y la salud de la polis? ¿Y cómo inmunizarlas contra la amenaza constante de invasión, la enfermedad y el contagio de todo tipo de elementos desestabilizadores? ¿Dónde residen dichos elementos y cómo supervisarlos?

Desde comienzos del siglo XX, la investigación erudita parece coincidir en el sentido de la crítica platónica a la experiencia poética de la Grecia arcaica. Sabemos que el filósofo aspira a una empresa titánica, a una revolución cultural sin precedentes que pretende sustituir el conglomerado de la sociedad homérica por una nueva paideia orientada a la autonomía, la autarquía y la abstracción racional. Siguiendo los pasos de PARRY 1928, autores como HAVELOCK 1963 y ONG 1987 insisten en el papel crucial que, en dicha revolución, juega la crítica de la poesía mimética como instrumento de transmisión cultural en una sociedad sin escritura, como técnica de perpetuación de los valores tradicionales y como actividad ejemplarizante mediante la articulación rítmica de recitación, música y danza ${ }^{12}$. En efecto, en una sociedad oral, el relato rítmico y teatralizado se convierte en el vehículo privilegiado de transmisión de cultura, pero también de experiencia extática y de liberación pulsional inconsciente. Y es quizá en este punto donde podemos encontrar las raíces del antimimetismo de Platón y de sus diferentes procesos de reactivación en diversas tradiciones de pensamiento ${ }^{13}$ :

Lo que repugna a Platón de una sociedad construida a través de sus poemas es que se trata de un cuerpo social sin individuos libres. Es más, podríamos decir que se trata de un cuerpo social sin individuos propiamente dichos. Esta es una de las características más destacadas de estos órdenes a los que podríamos llamar "sociedades estéticamente conformadas" o "sociedades densamente orgánicas” (ALEGRE 2012, 42).

\footnotetext{
12 Además de Havelock y Ong, los trabajos de Parry han sido brillantemente expuestos y continuados por LORD 1960, KIRK 1968 y PAVESE 1972 y 1974.

13 «Las reactivaciones de la actitud antimimética han sido innumerables: la encontramos por ejemplo en la iconoclasia medieval (bizantina); resurge en las advertencias jansenistas contra el teatro o la pintura figurativa; es de nuevo ella quien guía, al menos en parte, las reflexiones del romanticismo de Jena sobre la poesía; algunas décadas más tarde, intenta descalificar la fotografía; en el siglo XX, forma parte del programa de los inventores del arte abstracto (Kandinsky y Mondrian) y es utilizada como criterio descalificatorio por una (gran) parte de la crítica en el terreno de las artes plásticas; es la base del teatro épico de Brecht y ha alimentado la mayor parte de las polémicas "antirrealistas" y "antinaturalistas" en el terreno de la ficción literaria...; en fin, en la actualidad más inmediata, es ella otra vez la que fundamenta una gran parte de las reticencias que provoca el desarrollo de los medios digitales (y, especialmente, de las imágenes de síntesis y los dispositivos de realidad virtual)» (SCHAEFFER 2002, 3-4).
} 
Allí donde el vehículo de toda cultura y el soporte de todo valor reside en la repetición mimética, automática y memorística de un pasado remoto jamás sometido a la mirada crítica del pensamiento escéptico y la reflexión abstracta, no encontraremos más que comunidades serviles y heterónomas incapaces de reflexionar sobre sí mismas, sobre su pasado y sobre sus posibilidades futuras. La posibilidad de fuga cultural y mental de un modelo semejante, que imperó durante siglos en la mentalidad griega arcaica, pasa, precisamente, por la sustitución de la memoria inercial por el análisis conceptual; por el relevo de la repetición rítmica e irracional de los contenidos, actitudes, normas y valores de la tradición inmemorial, por una construcción inédita de nuevos horizontes experienciales basados en el debate dialógico. El reemplazo, en definitiva, de la imitación (hechizante, venenosa y traidora) por el conocimiento (resultado de un esfuerzo dialéctico en común orientado al descubrimiento de la verdad en el orden epistémico, ético y político).

La República de Platón supone, entonces, una auténtica revolución ontológica, epistemológica, política y pedagógica que, en buena medida, depende de una reforma cultural extrema y de un nuevo sistema educativo. Si Tucídides está en lo cierto (III $82,2,6,8$ y V 105, 2) y el género humano se ve continuamente arrojado al vértigo de la perdición por su tendencia a la satisfacción inmediata del deseo y por una excesiva voluntad de imperar que, además, se acompaña del ansia desmedida de aplausos y honores, entonces, el proyecto educativo y reformador de Platón debe articularse negativamente sobre la necesidad de censurar, neutralizar y minimizar las tendencias corporales más peligrosas para el gobierno de uno mismo y de la polis. Esa disposición irracional, como sugiere $\operatorname{KLOSKO}(2006,124-127)$, deberá constituir el primer objeto de atención de toda reforma cultural. En efecto, la educación negativa de las pasiones sensibles será condición de posibilidad de toda armonía individual y colectiva. Y esa educación negativa quedará instalada en el proceso educativo desde la más tierna infancia mediante un proceso de supervisión, censura y regulación de aquellos estímulos que con mayor virulencia contribuyen a la pérdida de la armonía, la mesura y la salud de la unidad psíquica y social, a saber: los estímulos poéticos, miméticos y artísticos que, mediante el mecanismo de la identificación psico-afectiva, sumergen al individuo en la corriente de la experiencia sensible y diluyen su capacidad para

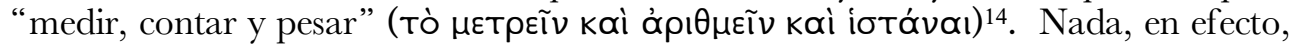
tan peligroso para la salud y la unidad de la psique como su constante exposición situacional a los estímulos del arte en todas sus formas y, particularmente, en su modo mimético o imitativo. ¿Cómo es posible que la reproducción teatralizada de escenas

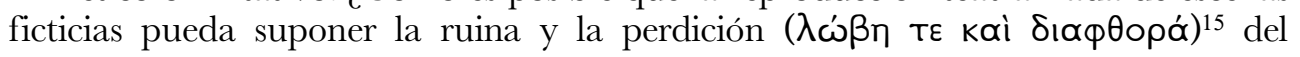

\footnotetext{
${ }^{14}$ R. 602d-c; cf. Euthphr. 7b, Prt. 356b y Phlb. 55c.

${ }^{15}$ Como recuerda Gastaldi (2007, 94 n. 3), $\lambda \omega \dot{\beta} \eta$ es un término particularmente violento que indica un «danno radicale, irreversibile». En Leyes 890c 1, Platón lo emplea para describir los efectos perniciosos del ateísmo materialista. Asimismo, encontramos un claro ejemplo de los estragos que, a juicio de Ánito, la sofísitica produce en las mentes juveniles en Menón 91c 1-3: «Por Herácles, cállate, Sócrates. Que ninguno de los míos, ni mis amigos más cercanos, ni mis conocidos, conciudadanos o extranjeros, caiga en la locura de ir tras ellos [los sofistas] y hacerse arruinar, porque evidentemente son la ruina y la
} 
auditorio, el individuo y la ciudad? (595b-c). ¿En qué consisten los poderes supuestamente devastadores de la mímesis y cómo consigue el genio de Platón reciclarlos políticamente en el seno de su república ideal? Trataremos de responder a estas preguntas en el siguiente apartado.

2. El daño y la ruina: Platón y el pathos bifronte de la mímesis

En su ensayo cPor qué la ficción?, Jean Marie Schaeffer nos recuerda que las artes miméticas (de semejanza, imitación y fingimiento lúdico) siempre han sido abordadas con cierta ambivalencia en el pensamiento Occidental: la ambivalencia característica de la atracción frente al abismo. Pocas cosas, en efecto, tan sugerentes como el juego inmemorial de los simulacros y la tentación de ser hechizados, seducidos o arrebatados por las fuerzas de la ficción. Dichas fuerzas, sin embargo, y en virtud de la violencia irrevocable del rapto que procuran, generan desde antiguo una severa desconfianza:

¿no hay algo inquietante en el hecho de que podamos dejarnos subyugar así por los
simulacros? Su poder parece irresistible: aun sabiendo, en el momento de exponernos
a sus encantos, que se trata de simulacros -precisamente esa certeza nos ha motivado
en primer lugar a exponernos a ellos-, nos dejamos atrapar. Esa capacidad que tienen
las apariencias de neutralizar nuestras instancias de “control racional”, ¿no constituye
un motivo más que suficiente para desconfiar de toda imitación, aunque sea artística?...
¿̇no deberíamos contrarrestar su eficacia mediante procedimientos de distanciamiento
irónico, mediante una ruptura del efecto de realidad, mediante una deconstrucción de
los mecanismos de alienación que pone en marcha? (SCHAEFFER 2002, 3).

Este pasaje resume a la perfección los elementos constitutivos de la mimesofobia: el miedo a la relación mimética entendido como miedo al secuestro y al contagio del arte imitativo; el miedo del arte como terror ante la perspectiva de subyugación del sujeto mediante la neutralización de sus capacidades racionales y gracias a la proliferación de una serie de mecanismos estimulación afectiva que conducen irremediablemente a la alienación y la disolución de toda forma de autogobierno. Dichos elementos suelen insertarse, además, en un marco axiológico de evaluación moral que posiciona al discurso anti-mimético en el corazón de cualquier proyecto integral de reforma psico-política. Se trata, en efecto, de enseñar al que no sabe y de orientar al que está perdido; de liberar al prisionero y de curar al enfermo; de iluminar al que transita en la oscuridad o de hacer despertar al que está hechizado y poseído en el mundo de los sueños:

[E]1 discurso anti-mimético es antes que nada un discurso de pedagogo [...] los habitantes de la Caverna inducidos a error por las sombras, los paganos idólatras, los niños que viven en una inmediatez ingenua no mediatizada aún por el ejercicio de la razón, los oprimidos incapaces de descubrir por sí mismos los mecanismos de la alienación social que la identificación mimética reproduce y refuerza, el "gran público"

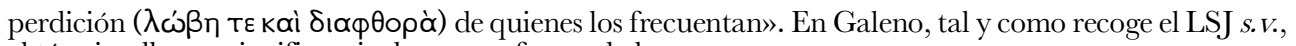
el término llega a significar, incluso, una forma de lepra. 
manipulado por el cine "hollywoodiense", los "sujetos posmodernos" lobotomizados por las tecnologías digitales [...]. Es también un discurso de denuncia: si hay víctimas, tiene que haber un lobo. Por supuesto, este último adopta diversas formas según las épocas: actualmente, es el comerciante, por ejemplo el productor hollywoodiense o el tecnocapitalista de Silicon Valley; en otras épocas era el actor de teatro o, incluso, como en Platón, el poeta trágico y el pintor. Pero cualesquiera que sean sus ropajes, el lobo imitador persigue siempre la misma meta: corromper los corazones y alienar la razón (SCHAEFFER 2002, 5).

Comenzamos esta sección citando in extenso a Jean-Marie Schaeffer por dos razones fundamentales. En primer lugar, porque el pensador francés cree encontrar en la obra de Platón el origen y, en buena medida, el límite de las posibilidades teóricoprácticas de la mimesofobia y el anti-mimetismo en Occidente (SCHAEFFER 2002, 141). Nuestra propuesta suscribe el eje argumental de todo el ensayo. Pero los textos de Schaeffer son relevantes por una segunda razón: el empleo constante, premeditado y filosóficamente relevante del lenguaje metafórico en el esclarecimiento de las claves anti-mimetismo y la mimesofobia. Unas claves cuya fragua conceptual encontramos diseminada en diversos lugares del corpus platónico, pero que reciben su expresión más fértil en el Ión y en los libros II, III y X de la República de Platón ${ }^{16}$.

En el Ión, y al hilo de la crítica de Sócrates a la poesía homérica como una forma irracional de inspiración divina, encontramos una de las metáforas más célebres de toda la producción platónica. La imagen de la piedra magnética o heraclea, empleada por Sócrates con el fin de mostrar a Ión que el rapsoda es movido no por el conocimiento de un arte o de una técnica, sino por una fuerza irracional que, al modo de los imanes, arrastra inevitablemente al artista y a cualquier auditorio preso de su influjo. La Musa a la que los distintos grupos de poetas itinerantes dicen servir -y por cuya boca, supuestamente, hablan- aparece identificada con una fuerza originaria que atrae hacia sí al modo de un imán. Una pujanza que es capaz de traspasar sus propiedades de arrastre a otros cuerpos y de hacer que estos, a su vez, extiendan la cadena imantada más allá de sus propios límites:

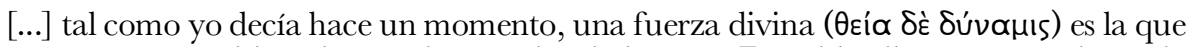
te mueve, parecida a la que hay en la piedra que Eurípides llamó magnética y la mayoría, heráclea. Por cierto, que esta piedra no sólo atrae a los anillos de hierro, sino que mete en ellos una fuerza tal que pueden hacer lo mismo que la piedra, o sea, atraer otros anillos, de modo que a veces se forma una gran cadena de anillos de hierro que penden unos de otros. A todos ellos les viene la fuerza que los sustenta de aquella piedra (Io. 533d 1-e 5).

16 Emplearemos los términos “arte”, “poesía”, “arte mimético” y "poesía mimética” en un sentido amplio, de modo que puedan incluir todos los tipos de representación artística que aparecen recogidos en la República: el género épico, el ditirambo, la tragedia y también la pintura, que, como es sabido, ocupa un lugar central en el desarrollo del libro X. Sobre las dificultades de relacionar el arte pictórico con el arte imitativo en $R$. X, ver Moss 2007 y 2008. Para una idea de conjunto acerca de las relaciones entre Platón y la mímesis, ver ANNAS 1981, 79-101 y 335-355, DALFEN 1974, DestréE 2012, Halliwell 1988 y 2009, Janaway 1995, Kardaun 2014, Nadaff 2002, Palumbo 2008, Rosen 1988, TeISSERENC 2005, ThIELE 1991 y Verdenius 1978. 
La mímesis aparece caracterizada, en primer lugar, como una fuerza de atracción y un instrumento de poder. Una fuerza, sin duda, irresistible. Una pujanza que, como decíamos, parece capaz de someter a los cuerpos ubicados en su ámbito de influencia y de traspasarles su potencia de arrastre. En otras palabras: una fuerza indomable y contagiosa que propaga su potencia de manera ilimitada, tal y como un imán podría hacer con una cadena de objetos metálicos:

Así, también, la Musa misma crea inspirados ('̇v日éous), y por medio de ellos empiezan a encadenarse otros en este entusiasmo. De ahí que todos los poetas épicos, los buenos, no es en virtud de una técnica por lo que dicen todos esos bellos poemas, sino porque

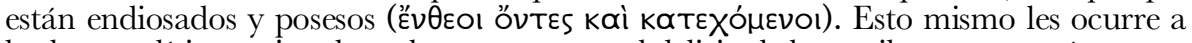
los buenos líricos, e igual que los que caen en el delirio de los coribantes no están en sus

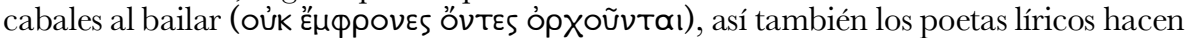
sus bellas composiciones no cuando están serenos, sino cuando penetran en las regiones de la armonía y el ritmo poseídos por Baco [...]. Y si la divinidad les priva de la razón y se sirve de ellos como de sus profetas y adivinos es para que, nosotros, que los oímos, sepamos que no son ellos, privados de la razón como están, los que dicen cosas tan excelentes, sino que es la divinidad misma quien las dice y quien, a través de ellos, nos habla [...]. Con esto, me parece a mí que la divinidad nos muestra claramente, para que no vacilemos más, que todos estos hermosos poemas no son de factura humana ni hechos por los hombres, sino divinos y creados por los dioses, y que los poetas no son más que intérpretes de los dioses, poseídos cada uno por aquel que los domine (533e 5$-535 a)$.

Vemos que, además de la atracción y la propagación, la fuerza poética es vinculada por Sócrates al orden divino del arrebato, la posesión y el entusiasmo irracional. El origen de la poesía y del encadenamiento afectivo que promueve su capacidad de contagio no residiría, entonces, en las facultades racionales del ser humano, sino en la violencia del rapto divino. La Musa misma se nos presenta como una fuerza arrastre que, simultáneamente, opera como un germen de contagio y una forma de delirio irracional ligado a las figuras de la posesión, la ebriedad, la ausencia de razón y la dominación. Estas figuras parecen sugerir en Platón que la relación mimética, la actividad poética y los poemas mismos que de ellas derivan no son más que una forma de servidumbre. Una forma dulce y placentera ${ }^{17}$ que, sin embargo, encadena a los poetas y a sus auditorios presentes (y tal vez futuros) al hechizo de potencias alienantes que los desposeen de sí mismos y diluyen su identidad en el arrebato báquico de la corriente poética. Por eso, recuerda Sócrates, un hombre libre ha de temer más la esclavitud que la propia muerte ${ }^{18}$, porque la muerte es sin duda preferible a la vida falsa inmersa en el simulacro.

Si acudimos a la República, nos encontramos con un pensamiento metafórico muy similar. Como es sabido, estos libros se centran en la regulación estricta del canto

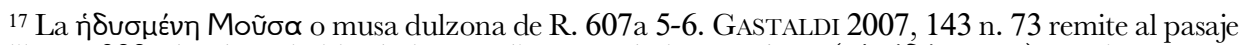

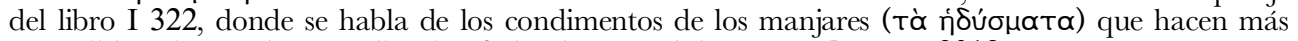
apetecibles a los productos culinarios. Sobre la musa dulzona, ver BOTTER 2018.

${ }^{18}$ R. 387b 4-5. 
poético y de los modos adecuados del mismo dentro de una ciudad perfecta. Se trata de responder a la pregunta acerca de cómo hablar y cómo no hablar de los dioses en nuestra república; de cómo cantar y cómo no cantar ni representar a la divinidad y a los mortales en nuestra comunidad política deseada. El sólo hecho de que sea necesario regular educativamente los relatos y los mitos que deben ser narrados y escuchados en una comunidad como la descrita por Sócrates contribuye a apuntalar la tesis que nos viene interesando: precisamente porque la actividad mimética opera como la fuerza de arrastre que caracteriza a piedra magnética, resulta necesario supervisar la práctica de la mímesis en una ciudad que se quiera sana y verdadera. La retórica y la metafórica del contagio comienzan hacer acto de presencia en los pasajes de la República y asumen, además, una función importante en términos educativos, pues las fábulas forjan, moldean y esculpen las almas de los ciudadanos desde la más tierna infancia:

¿Y no sabes que el principio es lo más importante en toda obra, sobre todo cuando se trata de criaturas jóvenes y tiernas? Pues se hallan en la época en la que se dejan moldear

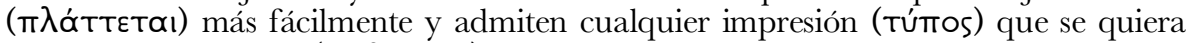
dejar grabada en ellas ( $R .377 \mathrm{~b}-\mathrm{c})$.

Los peligros de la imitación nacen con el proceso educativo mismo mismo. A juicio de Sócrates, la narración puede causar sobre la mente en formación los mismos estragos que una fiera salvaje sobre el cuerpo de sus víctimas. El lobo imitador devora el corazón y la razón, introduciéndose subrepticiamente en la ciudadela interior: « ¿ No has observado que, cuando se practica durante mucho tiempo y desde la niñez, la

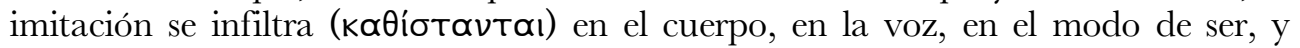
transforma el carácter alterando su naturaleza?» ${ }^{19}$. La imitación, en definitiva, parece «causar estragos $(\lambda \omega \dot{\beta} \eta)$ en la mente de cuantos la oyen si no tienen como contraveneno el conocimiento de su verdadera índole» ${ }^{20}$.

Como puede verse en estos ejemplos, el pensamiento metafórico de Platón no sólo es constante, lúcido y hermoso, sino también inquietante. Tan inquietante, al menos, como las figuras lupinas del riesgo sugeridas por Schaeffer al comienzo de este apartado. En efecto, el tipo de metafórica que se impone en el desarrollo de los pasajes dedicados a la crítica del arte coincide con lo acabamos de llamar "retóricas del contagio": un conjunto de procedimientos discursivos extremadamente eficaz orientado a la construcción de una figura conceptual que cumpla la función de un enemigo infeccioso del que es necesario protegerse y cuyos efectos son potencialmente devastadores para toda forma elemental de salud, de unidad psíquica y de estabilidad social. Un Hannibal ad portas omnímodo e imperceptible que desata el miedo irracional de cualquier de auditorio ante la inminencia del desastre, la contaminación y el contagio. Un agente infeccioso, en definitiva, cuya virulencia debe justificar el

\footnotetext{
${ }^{19} R$. III 395d $1-5$.

${ }^{20} R$. X 595b-c.
} 
empleo de todo tipo de estrategia gubernamental de orden profiláctico y sanador. Las retóricas del contagio serían, entonces, aquellas modalidades discursivas que, dentro de una determinada propuesta, nacen al servicio de la propagación del miedo a la infección de la comunidad y de la garantía, por parte del Estado, de la institución de mecanismos para su neutralización y su derrota.

La tesis de Platón es clara: la mímesis es una epidemia y una fuente de contagio y, por tanto, el foco de la enfermedad en el seno de toda comunidad política. En concreto, en el seno de toda comunidad política que, como la Grecia tradicional, haya estado sistemáticamente expuesta a su influjo debido al carácter singular de las comunidades orales y al papel central que en ellas ocupa la estirpe de los aedos. El conglomerado al que se enfrenta Sócrates en República es, entonces, el de un cuerpo social enfermo sostenido por elementos irracionales (atracción, arrebato e identificación psico-afectiva) que, además, expanden su influencia ilimitadamente por cuanto están ligados a la satisfacción de los placeres sensibles. Una influencia que, por supuesto, va mucho más allá del plano de la experiencia estética y la existencia individual. El empleo de la retórica del contagio en el marco de la crítica de la poesía tiene un importante contenido político: no se trata de instalar en el auditorio un miedo infantil y meramente psicológico frente a las formas tradicionales del arrebato artístico (el lobo del cuento). Se trata de revolucionar la concepción y la experimentación de las pasiones comunes ligadas a la experiencia poética. En efecto, la poesía griega primitiva (y, con ella, la cultura homérica en su totalidad) depende de la identificación y la perpetuación placentera, alegre y sensual de la comunidad en la representación de sus viejos mitos. Y ese placer mimético políticamente arriesgado es el que tanto preocupa a Platón. Hasta ahora hemos insistido en la importancia de la mímesis como instrumento de transmisión, como técnica de perpetuación y como actividad ejemplarizante acompañada de recitación, música y danza. Pero no hemos subrayado su importancia como fuente curativa de placer sensual, de liberación pulsional y de catarsis psicológica y social. Desde un punto de vista funcional, la poesía conserva y transmite la memoria y el conglomerado de la tradición y de sus normas fundamentales mediante un complejo mecanismo de recitación rítmica que implica factores orgánicos y físicos (HAVELOCK 1994, 148). Pero desde el punto de vista no funcional, además de dicha transmisión, la poesía se convierte en una fuente de placer hipnótico:

Los mecanismos de la poesía griega significaban una movilización de los recursos inconscientes, en ayuda de los conscientes. Los diversos reflejos motores, a pesar de la complejidad de su interacción, estaban organizados de modo que pudiesen operar sin ninguna actividad mental por parte del sujeto. Ello quiere decir que -como ocurre en el caso de los reflejos del aparato sexual o del digestivo- estos reflejos eran altamente sensuales y estaban muy estrechamente ligados con los placeres físicos. Es más: estaban capacitados para otorgar al sujeto humano un tipo específico de placer. La regularidad de la ejecución traía consigo un determinado efecto hipnótico que aliviaba las tensiones físicas del cuerpo y, con ellas, también las mentales, los miedos, las ansiedades y la incertidumbre que a todos nos toca padecer en este valle de lágrimas [...]. Cabe por 
consiguiente llegar a la conclusión de que la tecnología utilizada hacía que la recitación de la enciclopedia tribal se trocase en un acto de esparcimiento de la tribu (HAVELOCK 1994, 149).

A diferencia del mundo moderno y de la comunidad diseñada por Platón en la República, las sociedades construidas sobre el poema favorecen la identificación entre placer y deber, entre alegría y cumplimiento de la norma, entre regocijo y ley. Luis Alegre (2017, 45-48) habla de un "vínculo orgánico entre virtud y felicidad":

... el eterno empeño de las sociedades estéticamente conformadas es conseguir, por decirlo así, que las normas se cumplan solas [...]. En efecto, las sociedades densamente orgánicas se caracterizan por un intento de conformar la sensibilidad misma para ajustarla al modelo de las normas que tendrá que cumplir (ALEGRE 2017, 46).

La identidad de los miembros de la comunidad primitiva, entonces, depende en buena medida de la configuración mimética y narrativa de su deseo. Eso que la mímesis contagia mediante la teatralización de episodios ficticios y de personajes inmemoriales es, precisamente, el deseo de su eterna repetición. En otras palabras: la normatividad del pasado se reproduce íntegramente en cada una de las ejecuciones artísticas del presente y esa ejecución constituye una fuente de placer y asueto en la que la comunidad se siente plenamente identificada consigo misma. La mímesis, en clave pre-platónica, vehicula un pathos específico que parece convertirse en una pasión política por derecho propio, pues, como recuerda ARTETA 2003, satisface las condiciones de la afección, la cognición y la acción práctica resultativa. La mímesis parece estar asociada i) a una emoción placentera y alegre que, como tal, busca ser perpetuada (componente afectivo); ii) a una percepción cognitiva por parte del auditorio de la identidad entre el valor de la acción teatralizada y el valor de la acción cotidiana que se rige, precisamente, por el modelo normativo interpretado (componente epistémico o cognitivo); y iii) a una acción derivada de dicha valoración epistémica asociada al placer (componente activo). A juicio de Platón, el peligro de la mímesis reside precisamente aquí: las acciones individuales que se derivan del pathos homérico de la mímesis no conducen más que a la repetición acrítica del contenido mítico de la tradición y, en este sentido, carecen de todo valor epistémico y político, pues son acciones automatizadas que se perpetúan sin criterio racional alguno. No hay acción política en la tradición poética más allá del deseo animal e infantil de repetición, del anhelo de recuperación procurado por la belleza de la representación épica, trágica o pictórica. Desde esta perspectiva, el objetivo de Platón y de su retórica del contagio parece más titánico de lo que imaginábamos. El filósofo aspira a construir una plataforma conceptual que naturalice una relación inversa con el universo de la imitación: el miedo al contagio del arte debe sustituir ni más ni menos que a su deseo, al deseo de contagio. La mimesofobia debe abrirse paso entre la mimesofilia de la tradición oral. En otras palabras: la tarea de toda filosofía médica al servicio de la salud de la polis ha de ser la construcción de una pasión política común tan poderosa como la piedra heraclea. Una pasión que sea capaz de deshacer el 
vínculo entre gozo y deber y la intimidad entre pathos y nomos. Una pasión verdaderamente política que, ahora sí, estará basada en el entrelazamiento de un componente afectivo (el miedo), un elemento epistémico o cognitivo (la interpretación de la totalidad derivada de la crítica dialógica, argumentada y racional de la mímesis como epidemia) y una deriva de acción práctica (la acción virtuosa en el seno de una comunidad justa y racional). La instalación, mediante el discurso filosófico y la retórica infecciosa, de un pathos común (el miedo al contagio por entrega psicoafectiva al universo de la poesía imitativa) habilita un padecimiento común y automático que, en su rechazo, tiene por misión ligar la experiencia sensible de una comunidad, aunando sus valoraciones cognitivas y abriendo un horizonte homogéneo de expectativas. Sócrates aspira a desplazar la relación jovial, alegre y confiada del ciudadano griego ante la experiencia poética tradicional (que es el vehículo gozoso de la norma), hacia una relación fóbica y de rechazo ante la misma (porque es concebida como una fuente de contagio). Es decir: se trata de pasar del cumplimiento automático del deber por reproducción placentera de los contenidos míticos de la tradición al distanciamiento teórico, escéptico y crítico que permita analizar con detenimiento toda supuesta fuente de legitimación de la verdad teórica y de la acción ético-política. Sócrates quiere que la comunidad comparta ahora como temor lo que antes compartía como fuente de identificación afectiva, catarsis y relajación. En definitiva, se trata de arruinar, mediante la retórica infecciosa, ese pathos (a)político del placer ligado al cumplimiento de las normas inmemoriales y de sustituirlo por el miedo en común: el miedo al daño y la ruina. El miedo a la enfermedad de la polis, a los agentes infecciosos del arte y a la pérdida de uno mismo. Un miedo político frente a la alienación que convive con la esperanza de apertura de un espacio de salvación racional frente a todo aquello que no depende de nosotros mismos.

\section{Bibliografía}

- Textos antiguos

Platón (1901-1907), Platonis opera, I-V, I. Burnet (ed.), Oxford.

Tucídides (1901-1902), Thucydidis Historiae, I-II, H.S. Jones (ed.), Oxford.

- Textos modernos

Alegre, L. (2017), El lugar de los poetas, Madrid.

Annas, J. (1981), An introduction to Plato's Republic, New York-Oxford.

Arteta, A. (2003), en Arteta, A. - García Guitián, E. - Máiz, R. (eds.), Teoría política: poder, moral, democracia, Madrid, disponible online http://www.aurelioarteta.com/uploads/ 6/2/4/4/62447029/5._pa siones_pol\%C3\%ADticas.pdf

Biss, E. (2015), Inmunidad, Madrid.

Blumenberg, H. (2018, Paradigmas para una metaforología, Madrid. 


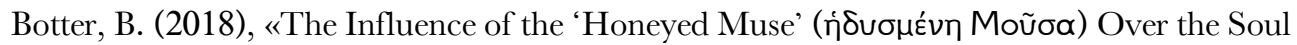
in Plato's Republio», en Boeri, M. - Kanayama, Y.Y. - Mittelmann, J. (eds.), Soul and Mind in Greek Thought, Suiza, 19-36.

Carrasco, N. (2010), «Pleonexía: el centro ausente de La república de Platón», Daimon. Revista Internacional De Filosofia 45, 71-84.

Dalfen, J. (1974), Polis und Poiesis. Die Auseinandersetzung mit der Dichtung bei Platon und seinen Zeitgenossen, München.

Destrée, P. (2012), «Plato on tragic and comic pleasures», en Denham, A. (ed.), Plato on art and beauty, New York, 125-141.

Eire, A.L. (1990), «La revolución en el pensamiento político de Tucídides (I)», Gerión 8, 89114.

Enguita, J.M. (2017), «Calicles, Nietzsche y el derecho natural del más fuerte», en Zamora Calvo, J.N. (ed.), Éticas griegas y filosofía contemporánea, Buenos Aires, 35-47.

Ferrari, G.R.F. (2003), City and Soul in Plato's Republic, Chicago-London.

Frías Urrea, R. (2000), «Calicles y el superhombre de Nietzsche (un comentario al Gorgias de Platón)», Revista de humanidades 7, 39-46.

Gastaldi, S. (2007), «La mimesis e l'anima», en Vegetti, M. (ed.), Platone. La Repubblica, traduzione e commento, VII, Libro X, Napoli, 93-149.

Halliwell, S. (1988), Plato: Republic X, UK.

Halliwell, S. (2009), The aesthetics of mimesis: Ancient texts and modern problems, Princeton.

Havelock, E. (1994), Prefacio a Platón, Madrid.

Janaway, C. (1995), Images of Excellence: Plato's Critique of the Arts, Oxford.

Kardaun, M.S. (2014), «The philosopher and the beast. Plato's fear of tragedy», PSyArt 18, 158-143.

Kirk, G.S. (1968), Los poemas de Homero, Buenos Aires.

Klosko, G. (2006), The development of Plato's political theory, Oxford.

Laín Entralgo, P. (1961), Enfermedad y pecado, Barcelona.

Lisi Bereterbide, F.L. (2008), «Los orígenes de la teoría política griega del Estado», Revista de historiografia 9, 19-26.

Lord, A.B. (1960), The Singer of Tales, Harvard.

Menzel, A. (1964), Calicles. Contribución a la historia de la teoría del derecho del más fuerte, México.

Moss, J. (2007), «What is imitative poetry and why is it bad?», en Ferrari, G.R.F. (ed.), The Cambridge Companion to Plato's Republic, Cambridge, 415-444.

Moss, J. (2008), «Appearances and calculations: Plato’s división of the soul», Oxford Studies in Ancient Philosophy 34, 35-68.

Nadaff, R. (2002), Exiling the poets: The production of censorship in Plato's Republic, Chicago.

Ong, W.J. (1987), Oralidad y escritura. Tecnologías de la palabra, México.

Palumbo, L. (2008), Mimesis. Rappresentazione, teatro e mondo nei dialoghi di Platone e nella Poetica di Aristotele, Napoli. 
Parry, M. (1928), L'Epitèthete traditionel dans Homère, Paris.

Pavese, C.O. (1972), Tradizioni e generi poetici della Grecia arcaica, Roma.

Pavese, C.O. (1974), Studi sulla tradizione epica rapsodica, Roma.

Rosen, S. (1988), The Quarrel between Philosophy and Poetry: Studies in Ancient Thought, New York.

Schaeffer, J.M. (2002), ¿Por qué la ficción?, Madrid.

Sonntag, S. (2012), La enfermedad y sus métaforas, Madrid.

Teisserenc, F. (2005), «Mimesis, narrative et formation du caractère», en Dixsaut, M. (ed.), Études sur la Republique de Platon, Paris.

Thiele, M. (1991), Negierte Katharsis: Platon - Aristoteles - Brecht, Frankfurt-Bern-New York-Berlin.

Vegetti, M. (ed.) (1998), La Repubblica, I-VII, Napoli.

Vegetti, M. (2012), Quince lecciones sobre Platón, Madrid.

Verdenius, W.J. (1978), «Plato's Doctrine of Artistic Imitation», en Vlastos, G. (ed.), Plato: A Collection of Critical Essays, Notre Dame (Indiana), 259-273.

Williams, B. (2006), «La analogía entre la ciudad y el alma en la República de Platón», en El sentido del pasado, México, 141-153. 